\title{
Acute effects of hypoxaemia, hyperoxaemia and hypercapnia on renal blood flow in normal and renal transplant subjects
}

\author{
R.A. Sharkey, E.M.T. Mulloy, S.J. O'Neill
}

Acute effects of hypoxaemia, hyperoxaemia and hypercapnia on renal blood flow in normal and renal transplant subjects. R.A. Sharkey, E.M.T. Mulloy, S.J. O'Neill. OERS Journals Ltd 1998.

ABSTRACT: The aim of this investigation was to study noninvasively the effects of hypoxaemia, hyperoxaemia and hypercapnia on renal blood flow in normal subjects and renal allograft recipients, i.e. with denervated kidneys. By comparing these two groups, the influence of renal innervation on any resulting changes in renal blood flow could be ascertained.

Nine normal and eight renal allograft recipients were studied. Each subject inhaled the following gas mixtures in order: room air, $10 \% \mathrm{O}_{2}$ (hypoxaemia), $10 \% \mathrm{O}_{2}+$ baseline $\mathrm{CO}_{2}$ (isocapnic hypoxaemia), $10 \% \mathrm{O}_{2}+$ high $\mathrm{CO}_{2}$ (hypercapnic hypoxaemia), $100 \%$ $\mathrm{O}_{2}$ (hyperoxaemia), $100 \% \mathrm{O}_{2}+$ baseline $\mathrm{CO}_{2}$ (isocapnic hyperoxaemia) and $100 \% \mathrm{O}_{2}$ + high $\mathrm{CO}_{2}$ (hypercapnia hyperoxaemia). Using Doppler ultrasonography, the pulsatility index (PI), an index of renovascular resistance, was measured at the various gas inhalation levels.

In normal subjects, the renovascular resistance increased in response to hypoxaemia, with a greater increase in response to hypercapnic hypoxaemia. Hyperoxaemia caused a decrease in renovascular resistance but this was abolished with the addition of $\mathrm{CO}_{2}$. There was a similar pattern in the PI response to the different gas inhalations in the renal transplant subjects, but these responses were attenuated in comparison with those of the normals.

In conclusion, renal denervation does not completely abolish the renovascular responses to inhaled oxygen and carbon dioxide.

Eur Respir J 1998; 12: 653-657.
Dept of Respiratory Medicine, Beaumont Hospital, Dublin, Ireland.

Correspondence: S.J. O'Neill

Dept of Respiratory Medicine

Beaumont Hospital

Dublin 9

Ireland

Fax: 35318376982

Keywords: Hypercapnia

hyperoxaemia

hypoxaemia

renal blood flow

renal denervation

Received: October 291997

Accepted after revision May 121998
Changes in arterial oxygen and carbon dioxide levels cause alterations in the renal blood flow. Studies have shown variable effects of hypoxaemia and increasing oxygenation on renal blood flow, although it is generally accepted that severe hypoxaemia reduces renal blood flow $[1,2]$. There is more general agreement on the effect of hypercapnia, which reduces renal blood flow in subjects with chronic obstructive pulmonary disease (COPD). Hypercapnia has also been shown to prevent improvement in renal blood flow with the administration of oxygen $[1,3]$. There are very few published studies looking at the acute effects of changes in inspired oxygen and carbon dioxide on renal blood flow in normal subjects $[4,5]$.

The mechanisms whereby alterations in oxygen and carbon dioxide levels influence renal blood flow are not fully understood. It is thought that the renal nerves and various hormones and neuropeptides including catecholamines, dopamine and endothelin are the main factors influencing the changes in renal blood flow $[3,6,7]$. In this study, the effect of different levels of inspired oxygen and carbon dioxide on renal blood flow was compared in normal subjects and in subjects postrenal transplantation, i.e. subjects with denervated kidneys. By comparing these two groups, it could be ascertained whether renal denervation abolished the renovascular responses to the gas inhalations. The development of Doppler ultrasonography has allowed the rapid, accurate, reproducible and noninvasive investigation of renal blood flow and is ideally suited for human studies.

\section{Methods}

\section{Subjects}

Nine normal and eight renal allograft recipients were studied. All participants were male. Each subject gave informed consent and the hospital ethics committee approved the study protocol. The normal subjects were recruited from the hospital medical staff. They were all in good health and none was taking medication.

The renal transplant subjects were recruited from the nephrology outpatient department. They were at least 18 months post-renal transplantation (mean 30 months), and had no history of cardiac or respiratory disease. Renal function was stable in each subject, with serum creatinine level $<250 \mu \mathrm{mol} \cdot \mathrm{L}^{-1}$ and no recent episodes of rejection. All subjects were receiving immunosuppressive therapy which included prednisolone, azothioprine and cyclosporin. Seven of the subjects were taking antihypertensive medication, consisting of a $\beta$-blocker in five cases and nitrates in two, and this medication was omitted for $24 \mathrm{~h}$ before the study. 


\section{Ultrasonography}

Each subject fasted for $6 \mathrm{~h}$ before the study. An Acuson 128 real-time ultrasound scanner (Acuson Corporation, Mountain View, CA, USA) with colour flow and pulsed scanning facility was used to carry out the Doppler ultrasound examinations [8]. In the normal subjects, the kidney was scanned via the translumbar route, with the subject seated, while the transplanted kidney was scanned via the transabdominal route, with the patient supine. The renal hilum was identified and a renal interlobar artery selected. From the sonogram produced, the integrated computer software calculated the pulsatility index (PI). The PI is obtained by calculating the difference between the peak systolic frequency shift (velocity) of the Doppler spectrum $(A)$ and the end-diastolic frequency shift $(B)$, which is then divided by the mean frequency shift (mean), such that $\mathrm{PI}=(A-B) /$ mean. $\mathrm{PI}$ is an index of resistance to flow distal to the point of sampling in the vascular bed; thus, it is an indirect index of the degree of vasoconstriction, rather than a direct measurement of renal blood flow [9]. The lower the PI, the lower the resistance to flow and, therefore, the greater the rate of flow [10]. In the author's centre, the coefficient of variation of PI is $2.05 \%$ [8] and each PI result presented is the mean of three measurements.

The PI was used in preference to measuring renal artery velocity directly, as this would require calculation of the angle between the beam of insonation and vessel wall and this angle has to be kept between $45^{\circ}$ and $65^{\circ}$. Technically, this angle is extremely difficult to reproduce in each pat-ient as the kidney moves with respiration and a limited time was available for each measurement. By using the PI, it is presumed that the angle of insonation is always $0^{\circ}$ therefore, it is much easier and quicker to record this measurement. The PI is independent of the vessel diameter and the angle between the Doppler beam and the vessel axis [9].

\section{Circuit}

Two $100 \mathrm{~L}$ Douglas bags were filled with a mixture of $10 \% \mathrm{O}_{2}$ and $90 \% \mathrm{~N}_{2}$. These were connected to a breathing circuit, to which room air, $100 \% \mathrm{O}_{2}$ and $100 \% \mathrm{CO}_{2}$ at varying flow rates could be added. The subjects breathed via a facemask which occluded the nose, and had one-way inspiratory and expiratory valves. End-tidal $\mathrm{CO}_{2}$ tension $\left(P\right.$ et,, $\left.\mathrm{CO}_{2}\right)$ was monitored by means of a $\mathrm{CO}_{2}$ sensor attached to the expiratory port. A Hewlett-Packard capnometer was used, which was calibrated before each study (Hewlett Packard, Waltham, MA, USA). Arterial oxygen saturation $\left(\mathrm{Sa}_{\mathrm{a}} \mathrm{O}_{2}\right)$ was monitored by means of a SensorMedics (Anaheim, CA, USA) pulse oximeter with a finger probe. The subjects held the facemask tightly in place, so that they could remove it quickly if they became distressed. The presence of air leaks was excluded by a stable $P$ et, $\mathrm{CO}_{2}$ reading. $P$ et, $\mathrm{CO}_{2}$ is the $\mathrm{CO}_{2}$ tension at the peak of exhalation [11], and in healthy humans, is approximately $0.13 \mathrm{kPa}(1 \mathrm{mmHg})$ lower than the alveolar $\mathrm{CO}_{2}$ tension. Therefore, $P$ et, $\mathrm{CO}_{2}$ can be used as an indirect way of recording arterial $\mathrm{CO}_{2}$ tension $\left(\mathrm{Pa}, \mathrm{CO}_{2}\right)$ [12].

The effect of hypoxaemia and hyperoxaemia alone and then with $\mathrm{CO}_{2}$ added was studied. To study the effects of changing oxygenation independently of changes in arterial $\mathrm{CO}_{2}$ levels, the $P$ et, $\mathrm{CO}_{2}$ was continuously monitored and the inhaled $\mathrm{CO}_{2}$ levels were adjusted as necessary to maintain the $P$ et, $\mathrm{CO}_{2}$ at the desired level. As the $P$ et,, $\mathrm{CO}_{2}$ fell on breathing $10 \% \mathrm{O}_{2}$, the inspired $\mathrm{CO}_{2}$ was titrated to bring the $P$ et, $\mathrm{CO}_{2}$ back to baseline levels. Each subject inhaled the following gas mixtures in order: room air, $10 \%$ $\mathrm{O}_{2}$ (hypoxaemia), $10 \% \mathrm{O}_{2}$-baseline $\mathrm{CO}_{2}$ (isocapnic hypoxaemia), $10 \% \mathrm{O}_{2}+$ high $\mathrm{CO}_{2}$ (hypercapnic hypoxaemia), $100 \% \mathrm{O}_{2}$ (hyperoxaemia), $100 \% \mathrm{O}_{2}+$ baseline $\mathrm{CO}_{2}$ (isocapnic hyperoxaemia) and $100 \% \mathrm{O}_{2}+$ high $\mathrm{CO}_{2}$ (hypercapnia hyperoxaemia). High $\mathrm{CO}_{2}$ was achieved by adding 1-2 L $\mathrm{CO}_{2} \cdot \mathrm{min}^{-1}$ to the $10 \%$ and $100 \% \mathrm{O}_{2}$ inhalations, sufficient to raise the $P$ et, $\mathrm{CO}_{2}$ by at least $1.5 \mathrm{kPa}$ from baseline. An attempt was made to reach the same level of $P$ et, $\mathrm{CO}_{2}$ during the $10 \%$ and $100 \% \mathrm{O}_{2}$ inhalations. Each gas inhalation was maintained for at least $10 \mathrm{~min}$, until a stable $P$ et, $\mathrm{CO}_{2}$ was reached, and the PI was then measured. There were no intervening rest periods between the various gas inhalations. The different gas mixtures were well tolerated by each subject and no significant side-effects were experienced. The $\mathrm{S}_{\mathrm{a}} \mathrm{O}_{2}$ was prevented from dropping below $80 \%$ during hypoxaemia by the addition of $\mathrm{O}_{2}$ to the circuit, if required.

\section{Data analysis}

The PI measurements during inhalation of different gas mixtures were compared using the Kruskal-Wallis test for nonparametric data. The Dunn's multiple comparison test was used, where appropriate, to determine the levels at which the changes in PI were significant. Numerical variables were compared between the normals and renal transplant subjects by the Mann-Whitney test for nonparametric data. Variables were also compared by means of least squares regression analysis. The results are given as mean \pm SD, and a $\mathrm{p}$-value $<0.05$ was considered significant.

\section{Results}

The mean age of the normal subjects was $27 \pm 2.6$ yrs and that of the transplant subjects was $35.2 \pm 5.36 \mathrm{yrs}(\mathrm{p}<$ $0.005)$. In the normals, the PI changed significantly in res-

Table 1. - Arterial oxygen saturation $\left(\mathrm{Sa}_{\mathrm{a}} \mathrm{O}_{2}\right)$, end-tidal carbon dioxide tension $\left(P\right.$ et, $\left.\mathrm{CO}_{2}\right)$ and changes in pulsatility in$\operatorname{dex}(\mathrm{PI})$ in normal subjects $(\mathrm{n}=9)$

\begin{tabular}{lllc}
\hline & $\begin{array}{c}\mathrm{Sa}_{\mathrm{a}} \mathrm{O}_{2} \\
\%\end{array}$ & $\begin{array}{c}\mathrm{Pet}, \mathrm{CO}_{2} \\
\mathrm{kPa}\end{array}$ & $\mathrm{PI}$ \\
\hline Baseline $\mathrm{Sa}_{\mathrm{a}} \mathrm{O}_{2}$ & $96.6 \pm 0.7$ & $5.1 \pm 0.6$ & $0.86 \pm 0.11$ \\
$\begin{array}{c}\text { Hypocapnic } \\
\text { hypoxaemia }\end{array}$ & $83.3 \pm 2.2^{* *}$ & $4.4 \pm 0.4^{* *}$ & $0.96 \pm 0.13$ \\
$\begin{array}{c}\text { Isocapnic } \\
\text { hypoxaemia }\end{array}$ & $84.2 \pm 3.3^{* *}$ & $5.1 \pm 0.5$ & $1.03 \pm 0.14$ \\
$\begin{array}{c}\text { Hypercapnic } \\
\text { hypoxaemia }\end{array}$ & $87.8 \pm 4.4^{* *}$ & $6.8 \pm 0.6^{* *}$ & $1.14 \pm 0.14^{*}$ \\
$\begin{array}{c}\text { Hypocapnic } \\
\text { hyperoxaemia }\end{array}$ & $98.6 \pm 0.4^{* *}$ & $4.0 \pm 0.6^{* *}$ & $0.77 \pm 0.1$ \\
$\begin{array}{c}\text { Isocapnic } \\
\text { hyperoxaemia }\end{array}$ & $98.4 \pm 0.7^{* *}$ & $5.1 \pm 0.5$ & $0.88 \pm 0.09$ \\
$\begin{array}{c}\text { Hypercapnic } \\
\text { hyperoxaemia }\end{array}$ & $98.4 \pm 0.9^{* *}$ & $6.8 \pm 0.5^{* *}$ & $1.01 \pm 0.12$ \\
\hline Data are & & \\
\hline
\end{tabular}

Data are shown as mean \pm SD. $* *: \mathrm{p}<0.01 ; *: \mathrm{p}<0.05$, change in variable from room air. 


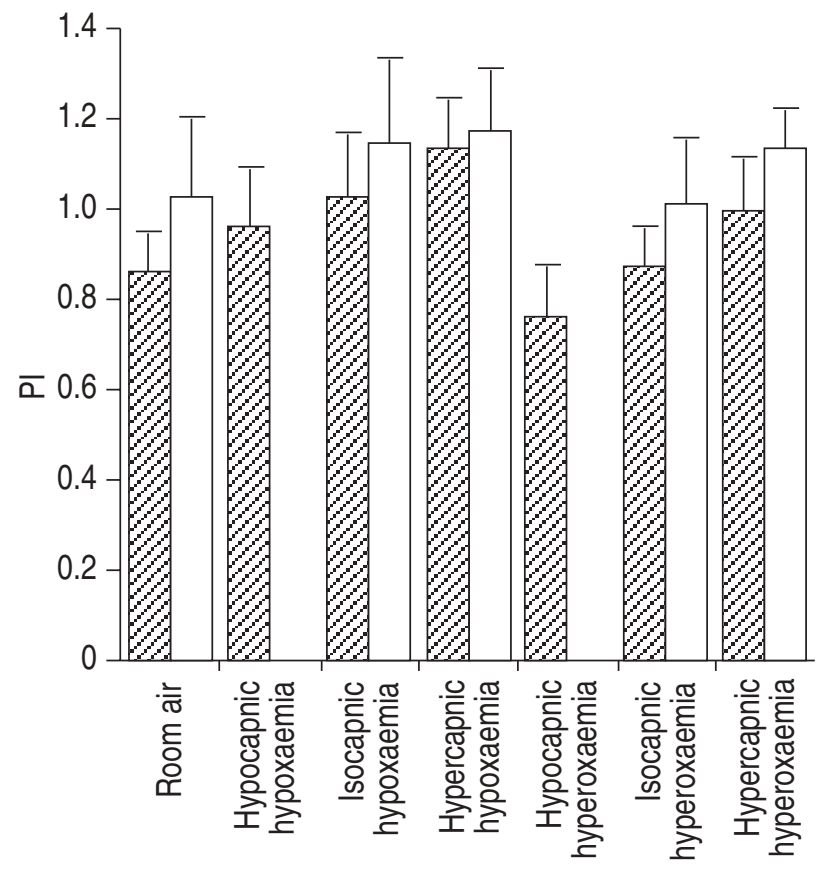

Fig. 1. - Change in pulsatility index (PI) in response to different levels of oxygen and carbon dioxide in the normal ( $Z 2)$ and renal transplant $(\square$ ) subjects. Data are shown as mean \pm SD.

ponse to changes in inhaled $\mathrm{O}_{2}$ and $\mathrm{CO}_{2}$ levels $(\mathrm{p}<0.001$ by Kruskal-Wallis testing). The PI rose during hypoxaemia (suggesting an increase in renovascular resistance) but this was not significant on Dunn's multiple comparison testing (table 1 , fig. 1). However, the $P$ et, $\mathrm{CO}_{2}$ simultaneously decreased, which may have opposed the renovascular response to hypoxaemia. There was a steady rise in PI as the $P$ et, $\mathrm{CO}_{2}$ was raised in the presence of hypoxaemia, inducing first isocapnic hypoxaemia and then hypercapnic hypoxaemia (table 1 ).

When $100 \% \mathrm{O}_{2}$ was inhaled, the $P$ et, $\mathrm{CO}_{2}$, contrary to expectations, fell in all except for one normal subject $(\mathrm{p}<$ 0.01 ). This was accompanied by a significant fall in renal vascular resistance when compared with the hypercapnic hypoxaemia level $(\mathrm{p}<0.001)$. However, when the $\mathrm{Pet}, \mathrm{CO}_{2}$ was corrected back to baseline levels, the PI also returned

Table 2. - Arterial oxygen saturation $\left(\mathrm{Sa}_{\mathrm{a}} \mathrm{O}_{2}\right)$, end-tidal carbon dioxide tension $\left(P\right.$ et, $\left.\mathrm{CO}_{2}\right)$ and pulsatility index $(\mathrm{PI})$ changes in renal transplant subjects

\begin{tabular}{|c|c|c|c|}
\hline & $\begin{array}{c}\mathrm{Sa}_{\mathrm{a}, \mathrm{O}_{2}} \\
\%\end{array}$ & $\begin{array}{c}P \text { et, } \mathrm{CO}_{2} \\
\mathrm{kPa}\end{array}$ & PI \\
\hline Baseline $S_{\mathrm{a}, \mathrm{O}_{2}}(\mathrm{n}=8)$ & $96.9 \pm 1.0$ & $4.5 \pm 0.5$ & $1.03 \pm 0.15$ \\
\hline $\begin{array}{l}\text { Hypocapnic } \\
\text { hypoxaemia }(\mathrm{n}=2)\end{array}$ & $86.5 \pm 2.1 * *$ & $4.4 \pm 0.2$ & $1.05 \pm 0.13$ \\
\hline $\begin{array}{l}\text { Isocapnic } \\
\text { hypoxaemia }(n=7)\end{array}$ & $83.4 \pm 5.1 * *$ & $4.5 \pm 0.5$ & $1.15 \pm 0.18$ \\
\hline $\begin{array}{l}\text { Hypercapnic } \\
\text { hypoxaemia }(n=6)\end{array}$ & $90.3 \pm 3.2 * *$ & $6.3 \pm 0.8 * *$ & $1.18 \pm 0.13$ \\
\hline $\begin{array}{l}\text { Hypocapnic } \\
\text { hyperoxaemia }(n=4)\end{array}$ & $99.0 \pm 0.0 * *$ & $3.2 \pm 0.6^{*}$ & $1.01 \pm 0.09$ \\
\hline $\begin{array}{l}\text { Isocapnic } \\
\text { hyperoxaemia }(n=8)\end{array}$ & $98.8 \pm 0.5 * *$ & $4.4 \pm 0.4$ & $1.02 \pm 0.14$ \\
\hline $\begin{array}{l}\text { Hypercapnic } \\
\text { hyperoxaemia }(n=8)\end{array}$ & $98.8 \pm 0.5^{* *}$ & $6.3 \pm 0.9 *$ & $1.15 \pm 0.08$ \\
\hline
\end{tabular}

Data are shown as mean \pm SD. **: $\mathrm{p}<0.01 ; *: \mathrm{p}<0.05$, change in variable from room air.
Table 3. - Comparison between the absolute and percentage changes in pulsatility index (PI) from baseline in both groups

\begin{tabular}{lccc}
\hline & Normal & $\begin{array}{c}\text { Renal } \\
\text { transplant }\end{array}$ & p-value \\
\hline Age yrs & $27.1 \pm 2.6$ & $35.3 \pm 5.4$ & $<0.001$ \\
Baseline PI & $0.86 \pm 0.11$ & $1.03 \pm 0.15$ & 0.02 \\
Isocapnic hypoxaemia- & $0.17 \pm 0.13$ & $0.12 \pm 0.09$ & Ns \\
baseline PI & $19.8 \%$ & $11.6 \%$ & \\
Hypercapnic hypoxaemia- & $0.29 \pm 0.13$ & $0.19 \pm 0.15$ & Ns \\
baseline PI & $33.7 \%$ & $18.4 \%$ & \\
Isocapnic hyperoxaemia- & $0.05 \pm 0.06$ & $-0.007 \pm 0.09$ & Ns \\
baseline PI & $5.8 \%$ & $-0.7 \%$ & \\
Hypercapnic hyperoxaemia- & $0.15 \pm 0.09$ & $0.09 \pm 0.13$ & Ns \\
baseline PI & $17.4 \%$ & $8.7 \%$ & \\
\hline Data &
\end{tabular}

Data are shown as mean \pm SD. Ns: nonsignificant.

to baseline levels. This suggests that hyperoxaemia had no effect on renovascular resistance when isocapnia was maintained. When hypercapnic hyperoxaemia was induced, the PI rose once more $(\mathrm{p}<0.05)$, suggesting that hypercapnia can override the beneficial effect of hyperoxaemia on renovascular resistance.

In the transplant subjects, there were qualitatively similar trends in the renovascular resistance responses to permutations in inhaled $\mathrm{O}_{2}$ and $\mathrm{CO}_{2}$, although these changes were not significant (table 2, fig. 1). In percentage terms, the PI responses in the transplant subjects were approximately half those of the normal subjects (table 3). There were no significant differences in the change in PI from baseline values between the two groups. In contrast to the normal subjects, the $P$ et, $\mathrm{CO}_{2}$ fell in only two transplant subjects in response to hypoxaemia and three subjects in response to hyperoxaemia, so these data are not shown in table 2 .

\section{Discussion}

In this study, in normal subjects, renovascular resistance increased in response to hypoxaemia, with a further increase when hypercapnic hypoxaemia was induced. Renovascular resistance decreased with hyperoxaemia, but there was a simultaneous fall in $P$ et, $\mathrm{CO}_{2}$ and when isocapnia was restored the fall in renovascular resistance was abolished. Hypercapnic hyperoxaemia caused a rise in renovascular resistance above baseline room air levels. These responses were diminished in the renal transplant subjects.

The primary aim of this study was to determine the changes in renal haemodynamics in response to varying levels of inspired oxygen and carbon dioxide. The secondary aim was to look at possible mechanisms for such changes. Thus, patients with renal transplants were studied to determine whether denervation abolished the renovascular responses. Histological studies have shown evidence of partial renal nerve regeneration in human renal transplant recipients [13]. However, a recent study has shown that, despite this regeneration, the human transplanted kidney remains functionally denervated [14].

In this study, the denervated subjects still had a partial response to varying oxygenation and $\mathrm{CO}_{2}$, suggesting that renal innervation is not solely responsible for the observed changes. It appears likely that other factors, such as circu- 
lating catecholamines and neuropeptides, also contribute to these renovascular responses in humans.

Hypercapnia caused a rapid and marked rise in renovascular resistance, suggesting a decrease in renal blood flow, and this occurred even in the presence of hyperoxaemia. The effect of hypercapnia on renal blood flow is well documented in animal studies [15-17] and in subjects with respiratory failure $[1,3,18]$ but, to our knowledge, no recent studies have been conducted on normal subjects. The most recent study, using methodology similar to the present study, showed that subjects with COPD and hypercapnic respiratory failure had a lower baseline renal blood flow than normocapnic hypoxaemic COPD subjects [3]. The hypercapnic subjects also failed to improve their renal blood flow with added oxygen, in contrast to the nor-macapnic subjects [3].

Hypercapnia can reduce renal blood flow by several potential mechanisms. Hypercapnia causes noradrenaline release via chemoreceptor stimulation and peripheral vasodilation, leading to renal vasoconstriction $[6,7,19]$. In addition to circulating noradrenaline, there is local release of noradrenaline in the kidneys via the efferent sympathetic nervous system [20]. In animal studies, the renal blood flow response to hypercapnia is abolished by renal denervation, suggesting that local neurogenic mechanisms play a dominant role in renovascular control in animals $[17,21,22]$. In the present study, in post-renal transplant subjects, i.e. those with denervated kidney, the renovascular response to hypercapnia was not totally abolished (tables 2,3), being 50-55\% of the change observed in normals. The lack of a significant difference between the two groups may be due to the small numbers in the study. Thus, while renal innervation plays some role in renovascular responses to hypercapnia, other factors such as circulating catecholamines and neuropeptides may also play a role.

Severe hypoxaemia is generally agreed to cause reduced renal blood flow in both humans and animals [1, 2224]; however, there are conflicting reports on the renal effects of moderate hypoxaemia [1-3, 25-29]. Fishman et al. [27] found that renal plasma flow increased with hypoxaemia and decreased during oxygen therapy. MANNIX et al. [25] and ReIHMAn et al. [28] found no change in ren-al blood flow with changing levels of oxygenation. These investigators studied COPD patients using para-aminohippurate or radioisotope clearance techniques to measure renal plasma flow, which may be inaccurate in the presence of the impaired renal tubular function that frequently occurs in severe COPD [30, 31]. Invasive devices and general anaesthesia, such as in the study of Fishman et al. [26], may also have interfered with the results obtained. A recent study using similar methodology to the present study showed that renal blood flow was reduced in subjects with hypoxaemic $\mathrm{COPD}$ (mean $\mathrm{Pa}, \mathrm{O}_{2} 6.9 \mathrm{kPa}$ ) compared with normal controls [2]. The present study is comparable to this, as the normal subjects reached an $\mathrm{Sa}_{\mathrm{a}} \mathrm{O}_{2}$ of $80-90 \%$, i.e. $\mathrm{Pa}, \mathrm{O}_{2}$ approximately $6.4-8.0 \mathrm{kPa}$. Few studies have been carried out on normals, however, a recent altitude study $\left(\mathrm{Sa}_{\mathrm{a}} \mathrm{O}_{2} 79-83 \%\right)$ showed that renal blood flow fell by $10 \%$ [4]. Almitrine bismesylate, a chemoreceptor stimulant that simulates the effect of hypoxaemia, increased renal blood flow in the first hour postadministration in normals, but it fell $4 \mathrm{~h}$ later [5].

Conflicting results were also found in early COPD studies of the effects of added $\mathrm{O}_{2}$ on renal blood flow [1, 25-
28]. A possible criticism of these studies was a failure to control for $\mathrm{CO}_{2}$ levels, which usually increase with $\mathrm{O}_{2}$ therapy. Two recent studies in COPD patients, also using Doppler methodology, showed improved renal blood flow when oxygenation was improved $[2,3]$. In the study by Howes et al. [3], the patients with hypercapnia failed to improve their renal blood flow in response to $\mathrm{O}_{2}$ administration, supporting the present findings. A preliminary study from our department of subjects with respiratory failure showed that renal blood flow increased acutely in res-ponse to inhaled $\mathrm{O}_{2}$ and this improvement was also rev-ersed by inducing hypercapnia [29].

The mechanisms whereby changes in oxygenation affect renal blood flow are not fully understood. In an animal study, the changes in renal blood flow induced by hypoxaemia were prevented by denervation of the peripheral chemoreceptors and markedly attenuated by renal denervation, but not influenced by adrenalectomy [32]. This suggests that changes in renal blood flow are caused by a reflex mechanism, dependent on the sympathetic nerves and chemoreceptor stimulation. The present results would be consistent with this finding, as attenuation of the changes in renovascular resistance in response to changes in $\mathrm{O}_{2}$ was seen in the subjects with denervated kidneys.

The mechanism whereby hyperoxaemia increases renal blood flow is unknown but may be due to inhibition of the chemoreceptors by hyperoxaemia (the opposite effect to hypoxaemia). Hormones and neuropeptides such as noradrenaline, endothelin and the renin-angiotensin activating system may also play a role, together with a direct effect of hyperoxaemia on the renal vessels.

Possible explanations (other than denervation) for the attenuated renovascular responses in the transplant subjects include their greater age, their impaired renal function, the effect of medication and possible narrowing of the renal artery anastamosis. However, there was no overt Doppler evidence of renal artery stenosis in the subjects and there was only a $20 \%$ difference in the baseline renal interlobar artery PI between the two groups. Ideally, the two groups should have been matched for age and serum creatinine, however, this does not detract from the finding that the transplant subjects still had a partial response to changes in $\mathrm{O}_{2}$ and $\mathrm{CO}_{2}$ despite renal denervation.

The $P$ et, $\mathrm{CO}_{2}$ rose in response to hyperoxaemia in all subjects apart from three of the transplant subjects. A possible explanation for this may be the roll-off effect. During the first few seconds of hypoxaemia, there is a rapid increase in respiratory frequency owing to stimulation of the carotid body. However, this increase falls to a plateau (hypoxic roll-off) which is between one-quarter and onethird of the peak value in adults [32]. It is thought that the respiratory frequency is inhibited from a central source, possibly the brainstem. The present subjects were made hypoxaemic, resulting in an increase in respiratory frequency, and $100 \%$ inspiratory oxygen fraction $\left(\mathrm{F}, \mathrm{O}_{2}\right)$ was applied soon afterwards. This hyperoxaemia could have inhibited the central inhibition on the respiratory frequency, leading to an increase, not the expected decrease, in respiratory frequency and a fall in $P \mathrm{et}, \mathrm{CO}_{2}$. Unfortunately, the respiratory frequency was not recorded during the study.

The $P$ et, $\mathrm{CO}_{2}$ fell in only two of the eight transplant subjects in response to hypoxaemia. The differing $P$ et, $\mathrm{CO}_{2}$ response to changing oxygenation in both groups could possibly 
be related to the effect of cyclosporin. Cyclosporin can affect the distal renal tubule, causing a tendency towards renal tubular acidosis, which could affect the exchange of hydrogen ions and bicarbonate.

It is well known that subjects with hypercapnic respiratory failure have a tendency to oedema, which is mediated in part via reduced renal blood flow [6-8]. Controlled oxygen therapy can help to resolve this oedema [20]. The findings of the present study are consistent with these clinical observations and provide a possible mechanistic ex-planation. However, the effects of acute changes in $\mathrm{O}_{2}$ and $\mathrm{CO}_{2}$ only were studied, and it is possible that more chronic changes in arterial blood gases may have a differing effect on renal blood flow.

In summary, in normal subjects, the pulsatility index increased with hypoxaemia, with a further increase with hypercapnic hypoxaemia. This suggests a fall in renal blood flow. Hyperoxaemia caused a decrease in the pulsatility index, which was abolished with the addition of $\mathrm{CO}_{2}$. These responses were attenuated, but not abolished in the renal transplant subjects, suggesting that renal innervation plays a role in the renal blood flow responses to acute alterations in inspired $\mathrm{O}_{2}$ and $\mathrm{CO}_{2}$.

\section{References}

1. Kilburn KH, Dowell AR. Renal function in respiratory failure. Effects of hypoxia, hyperoxia and hypercapnia. Arch Intern Med 1982; 127: 754-762.

2. Baudouin SV, Bott J, Ward A, Deane C, Moxham J. Short term effect of oxygen on renal haemodynamics in patients with hypoxaemic chronic obstructive airways disease. Thorax 1992; 47: 550-554.

3. Howes TQ, Deane CR, Levin GE, Baudouin SV, Moxham J. The effects of oxygen and dopamine on renal and aortic blood flow in chronic obstructive pulmonary disease with hypoxemia and hypercapnia. Am J Respir Crit Care Med 1995; 151: 378-383.

4. Anand I, Chandrashekhar Y, Rao S, et al. Body fluid compartments, renal blood flow, and hormones at $6000 \mathrm{~m}$ in normal subjects. J Appl Physiol 1993; 74: 1234-1239.

5. Ledderhos C, Quies W, Schuster R, Peters R. Renal hemodynamics and excretory function of healthy young men during stimulation of their peripheral arterial chemoreceptors by almitrine bismesylate. Biomed Biochim Acta 1987; 12: 1035-1042.

6. MacNee W. Pathophysiology of cor pulmonale in chronic obstructive pulmonary disease. Part I. Am J Respir Crit Care Med 1994; 150: 833-852.

7. MacNee W. Pathophysiology of cor pulmonale in chronic obstructive pulmonary disease. Part II. Am J Respir Crit Care Med 1994; 150: 1158-1168.

8. Sharkey RA, Mulloy EMT, Kilgallen IA, O'Neill SJ. Renal functional reserve in patients with severe chronic obstructive pulmonary disease. Thorax 1997; 52: 411-415.

9. Gosling RG, Dunbar G, King DH, et al. The quantitative analysis of occlusive peripheral arterial disease by a non-invasive ultrasonic technique. Angiology 1971; 22: $52-55$.

10. Evans DH, McDicken WM, Skidmore R, Woodcock JP. Doppler ultrasound. Physics, instrumentation and clinical applications. Chichester, Wiley, 1989; pp. 162-187.

11. Hess D. Capnometry and capnography: technical aspects, physiologic aspects, and clinical applications. Respir Care 1990; 35: 557-573.

12. Tobin MJ. Respiratory monitoring in the intensive care unit. Am Rev Respir Dis 1988; 138: 1625-1642.
13. Gazdar AF, Dammin GJ. Neural degeneration and regeneration in human renal transplant. N Engl J Med 1070; 283: 222-224.

14. Hansen JM, Abildgaard U, Fogh-Andersen N, et al. The transplanted human kidney does not achieve functional reinnervation. Clin Sci 1994; 87: 13-20.

15. Daugherty RM Jr, Scott JB, Dabney JM, Haddy FJ. Local effects of $\mathrm{O}_{2}$ and $\mathrm{CO}_{2}$ on limb, renal, and coronary vascular resistances. Am J Physiol 1967; 213: 1102-1110.

16. Zillig B, Schuler G, Truniger B. Renal function and intrarenal hemodynamics in acutely hypoxic and hypercapnic rats. Kidney Int 1978; 14: 58-67.

17. Stone JE, Wells J, Draper WB, Whitehead RW. Changes in renal blood flow in dogs during the inhalation of $30 \%$ carbon dioxide. Am J Physiol 1958; 194: 115-119.

18. Farber MO, Roberts LR, Weinberger MH, Robertson GL, Manfredi F. Abnormalities of sodium and $\mathrm{H}_{2} \mathrm{O}$ handling in chronic obstructive lung disease. Arch Intern Med 1982; 142: 1326-1330.

19. Ganong WF. Review of Medical Physiology, 17th Edn. Norwalk, CJ, Appleton \& Lange, 1995; pp. 615-624.

20. Anand IS, Chandrashekhar Y, Ferrari R, et al. Pathogenesis of congestive state in chronic obstructive pulmonary disease. Circulation 1992; 86: 12-21.

21. Gomori P, Kovach AGB, Takacs L, et al. The control of renal circulation in hypoxia. Acta Med Acad Sci Hung 1960; 16: 43-60.

22. Franklin KJ, McGee LE, Ullmann EA. Effects of severe asphyxia on the kidney and urine flow. J Physiol 1951; 112: 43-53.

23. Anderson RJ, Pluss RG, Berns AS, et al. Mechanism of effect of hypoxia on renal water excretion. J Clin Invest 1978; 62: 769-777.

24. Bruns FJ. Decrease in renal perfusion, glomerular filtration and sodium excretion by hypoxia in the dog. Proc Soc Exp Biol Med 1978; 159: 468-472.

25. Mannix ET, Dowdeswell I, Carlone S, Palange P, Aronoff GR, Farber MO. The effect of oxygen on sodium excretion in hypoxemic patients with chronic obstructive lung disease. Chest 1990; 97: 840-844.

26. Davies CE. The effect of treatment on the renal circulation in heart failure. Lancet 1951; ii: 1052-1057.

27. Fishman AP, Maxwell MH, Crowder CH, Morales P. Kidney function in cor pulmonale: particular consideration of changes in renal hemodynamics and sodium excretion during variation in level of oxygenation. Circulation 1951; 3: 703-721.

28. Reihman DH, Farber MO, Weinberger MH, et al. Effect of hypoxemia on sodium and water excretion in chronic obstructive lung disease. Am J Med 1985; 78: 87-94.

29. Sharkey R, Mulloy E, O'Neill S. The acute effects of added oxygen and carbon dioxide on renal blood flow in respiratory failure. Eur Respir J 1995; 8: Suppl 19, 389s.

30. Brenner BM, Zatz R, Ichikawa I. The renal circulations. In: Brenner BM, Rector FC Jr, eds. The Kidney. Philadelphia, PA, Saunders, 1986; pp. 93-123.

31. Farber MO, Weinberger MH, Robertson GL, Fineberg NS. The effects of angiotensin-converting enzyme inhibition on sodium handling in patients with advanced chronic obstructive pulmonary disease. Am Rev Respir Dis 1987; 136: 862-866.

32. Honig A, Wedler B, Zingler C, Ledderhos C, Schmidt M. Kidney function during arterial chemoreceptor stimulation III. Long-lasting inhibition of renal tubular reabsorption due to pharmacologic stimulation of the peripheral chemoreceptors with almitrine bismesylate. Biomed Biochim Acta 1985; 44: 1659-1672.

33. Weil JV, Zwillich CW. Assessment of ventilatory response to hypoxia: methods and interpretation. Chest 1976; 70: Suppl., 124-128. 